\section{Survey on the fatty acids profile of fluid goat milk}

\author{
Daniela Pittau, Romina Panzalis, \\ Carlo Spanu, Christian Scarano, \\ Enrico P.L. De Santis
}

Dipartimento di Medicina Veterinaria, Università di Sassari, Italy

\section{Abstract}

Fluid goat milk submitted to thermal treatment has interesting nutritional properties and a potential expanding market. The present study was aimed to conduct fatty acids profile characterisation of goat milk placed on market. Forty-nine fluid milk samples were collected: 12 pasteurised, 12 pasteurised at high temperature, 11 ultrahigh temperature (UHT) whole milk and 14 UHT semi-skimmed milk. Milk samples were collected at retail level from 7 different companies and from different production batches. After extraction and methilation, fatty acids (FAs) profile was determined on each sample using a gas chromatograph with flame ionisation detector (GC-FID) with high-polarity capillary column. The concentration $(\mathrm{g} / 100 \mathrm{~mL})$ of saturated fatty acids (SFAs), monounsaturated fatty acids (MUFAs), polyunsaturated fatty acids (PUFAs), trans fatty acids $(t$-FAs), and isomers of conjugated linoleic acid (CLA) was determined. N-6/n-3 ratio, atherogenic index (AI) and thrombogenic index (TI) were also assessed. Fluid goat milk lipid profile was characterised by SFAs ( $68.4 \%$ of total FAs), PUFAs (5.3\%), MUFAs (21.3\%), $t$ FAs $(3.6 \%)$ and CLA (0.8\%). The most represented fatty acids were: 16:0 (24.5\%), 9cis-18:1 (18.2\%), 18:0 (9.6\%), 14:0 (9.5\%), 10:0 (9.3\%) and 12:0 (4.5\%). Nutritional indices were 2.86.8 for $\mathrm{n}-6 / \mathrm{n}-3$ ratio; $2.3-2.9$ for $\mathrm{AI}$; and 2.7-3.2 for TI. Milk produced by small scale plants, with no milk fat standardisation, showed greater differences in fatty acid profile as compared to industrial plants milk. Large scale production is characterised by commingled bulk tank milk of different origins and then is more homogeneous. The whole goat milk supply chain should be controlled to obtain milk with fatty acids of high nutritional value.

\section{Introduction}

Fluid goat milk is a dairy product with a market of potential increasing relevance. Among milk constituents, fat has a great interest for human nutrition (Ervin et al., 2004), therefore it is essential the evaluation of milk fatty acids profile. Dietary fat intake of specific FAs is believed to affect human health and the occurrence of acute and chronic diseases (Huth et al., 2006). Several investigations studied the impact of milk fat in the prevention of cardiovascular disease (CVD) (Ulbricht and Southgate, 1991) and some types of cancers (Huth et al., 2006; Parodi, 2003). Whether saturated fatty acids (SFAs) play a positive or negative (Ulbricht and Southgate, 1991) role on human health is still debated. Some authors emphasise an holistic approach (Astrup et al., 2011). In fact, lauric (12:0), myristic (14:0) and palmitic (16:0) acids are considered responsible for the increase of plasmatic low density lipoprotein (LDL) and cholesterol levels, thereby increasing the risk of coronary heart disease (CHD) (Ulbricht and Southgate, 1991). On the contrary, unsaturated fatty acids (UFAs) of milk fat, especially some monounsaturated fatty acids (MUFAs) and polyunsaturated fatty acids (PUFAs), are considered having a positive influence on human health. Among MUFAs, oleic acid (OA) (9cis-18:1) seems to have a protective effect against cancer (Menendez et al., 2006). PUFAs, such as the essential fatty acids (EFAs) linoleic acid (LA) (9cis, 12cis-18:2) and $\alpha$-linolenic acid (ALA) (9cis, 12cis, 15cis-18:3), affect platelet aggregation and the risk of CVD (Haug et al., 2007). The dietary intake of long chain PUFAs (LC-PUFAs), and especially of n-3 such as eicosapentaenoic acid (EPA) (5cis, 8cis, 11 cis, 14cis, 17cis-20:5) and docosahexaenoic acid (DHA) (4cis, 7cis, 10cis, 13cis, 16cis, 19cis22:6) is proven to be effective in reducing the risk of CHD (Kris-Etherton et al., 2003). The importance of nutritional intake of these FAs must be evaluated considering the complex compensation mechanisms that occur in the human organism. In case of deficient diet in EPA and DHA or LA, EPA production is carried out through elongation of ALA (Defilippis and Sperling, 2006). A parameter for the determination of nutritional value of milk is the $n-6 / n$ 3 fatty acid ratio. The low intake of $n-3$ as compared to $n-6$, observed in western countries diet may promote the onset of chronic diseases such as CVD, cancer, autoimmune and inflammatory diseases (Simopoulos, 2002).

Trans fatty acids ( $t$-FAs) are naturally present in ruminant's milk fat. Their total content is lower and with different composition of isomers as compared to partially hydrogenated oils (Destaillats et al., 2008). High $t$-FAs intake has been associated with an increased risk of CHD and myocardial infarction (Ascherio et al., 1994). Vaccenic acid (VA) (11trans-18:1) is the most represented $t$-FAs in ruminant milk (Park et al., 2007). VA is the main precursor of rumenic acid (RA) (9cis, 11trans-18:2), the principal isomer of conjugated linoleic acid (CLA) in milk. The isomer 9cis, 11trans-18:2 positively affects the plasmatic lipid profile, reducing the risk of $\mathrm{CHD}$ and the onset of can-
Correspondence: Daniela Pittau, Dipartimento di Medicina Veterinaria, Università di Sassari, via Vienna 2, 07100 Sassari, Italy

Tel. +39.079 .229453 - Fax: +39.079 .229458 .

E-mail: dpittau@uniss.it

Key words: Fatty Acids, Fluid goat milk, GC-FID.

Conflict of interests: the authors declare no potential conflict of interests.

Received for publication: 28 March 2013.

Revision received: 3 May 2013.

Accepted for publication: 3 May 2013.

This work is licensed under a Creative Commons Attribution 3.0 License (by-nc 3.0).

(C) Copyright D. Pittau et al., 2013

Licensee PAGEPress, Italy

Italian Journal of Food Safety 2013; 2:e33

doi:10.4081/ijfs.2013.e33

cers (Bhattacharya et al., 2006). Ruminant milk and meat represent almost the exclusive source of CLA in human diet (Parodi, 2003). Characteristics of goat milk composition and their effects on human nutrition have been investigated in several reports (Park et al., 2007; Ceballos et al., 2009). Most of milk composition studies have been carried out on individual or bulk tank samples collected at farm level, while little information exist on fluid milk at retail level. Moreover, only few studies investigated goat's milk lipid composition (Barnes, 1951; Merlo, 2001). The objective of the present study was to evaluate the nutritional characteristics of fluid goat milk available on the market with regard to major fatty acids profile and concentration.

\section{Materials and Methods}

The survey was conducted between April and May 2012 on fluid goat milk samples marketed in Sardinia. A total of 49 samples, belonging to 7 different dairy plants, were collected at retail level. Milk samples originated from the same dairy plant were of different batches (Table 1). Milk samples were frozen at $-20^{\circ} \mathrm{C}$ until analysis. Lipid extraction was performed by a liquid/liquid technique with chloroform-methanol-water, according to Bligh and Dyer's modified method (1959). The methylation of FAs was obtained using sodium methoxide in methanol according to the procedure described by Cruz-Hernandez et al. (2004). The separation of the methyl esters of FAs (FAME) was performed by gas chromatograph Shimadzu GC-2010 (Shimadzu Italy, Milan, Italy) equipped with a flame ionisation 
detector (FID) and ionic liquid capillary column SLB-IL111 (100 m, $0.25 \mathrm{~mm}$, thickness 0.2 $\mu \mathrm{m})$ (Supelco, Bellefonte, PA, USA) (Delmonte et al., 2011).

The oven temperature was set at $80^{\circ} \mathrm{C}$ for 2 min, then at $168^{\circ} \mathrm{C}$ with a rate of $15^{\circ} \mathrm{C} / \mathrm{min}$, kept constant for $18 \mathrm{~min}$, increased to $5^{\circ} \mathrm{C} / \mathrm{min}$ up to $186^{\circ} \mathrm{C}$ and maintained constant for 33 min. The injector was maintained at $250^{\circ} \mathrm{C}$ and the detector at $280^{\circ} \mathrm{C}$. The injection port was used in split mode with a ratio of 100:1, with $1 \mathrm{~mL}$ injection volume. The carrier gas was $\mathrm{H}_{2}$ at a flow rate of $1.36 \mathrm{~mL} / \mathrm{min}$, while the gas for the detector were $\mathrm{H}_{2}$ at $30 \mathrm{~mL} / \mathrm{min}$, ultrapure air at $400 \mathrm{~mL} / \mathrm{min}$ and make-up gas $\mathrm{N}_{2}$ at $30 \mathrm{~mL} / \mathrm{min}$. The tritridecanoin (triglyceride 13:0) was used as internal standard (IS) and was added to milk before lipids extraction. The IS amount added to milk was about 0,0036 mg per mg milk. The individual identification of FAs was carried out through a comparison of the retention times determined throught the use of reference standard or those reported in the literature.

Total fat and FAs mean concentration were calculated as $\mathrm{g} / 100 \mathrm{~mL}$ of milk. FAs profile was also determined and expressed as \% of total FAs in milk. The atherogenic index (AI) and thrombogenic index (TI) were calculated according to Ulbricht and Southgate (1991).

\section{Results}

The dairy plants location, number and types of fluid milk collected are summarised in Table 1. Total fat content and main lipid fractions profile of fluid goat milk produced in the seven plants are reported in Table 2. Fresh pasteurised milk (plant A and B) showed a higher fat content as compared to the other types of fluid milk. Moreover, in fresh milk the higher absolute values for almost all the FAs were detected (Table 2). Goat milk average FAs profile was characterised by $68.4 \%$ of SFAs, $5.3 \%$ of PUFAs, $21.3 \%$ of MUFAs and $3.6 \%$ of $t$-FAs. The complete profile of analysed fatty acids is reported in Table 3 . The most represented FAs were 16:0 (24.5\%), 9c-18: 1 (18.2\%), 18:0 (9.6\%), 14:0 (9.5\%), 10:0 (9.3\%) and 12:0 (4.5\%). Pasteurised milk collected from dairy A was characterised by the higher content of ALA $(0.7 \%)$ and the lower content of $t$-FAs (3.1\%), in particular isomer $10 t-18: 1$ (0.2\%). These samples showed the highest value of TI (3.2). Pasteurised milk from dairy plant B showed the highest fat content and was characterised by the lowest concentration of SFAs (66.4\%), in particular myristic $(8.5 \%)$ and palmitic (23.3\%) acids. The FAs profile showed a concentration of short chain saturated fatty acids (SCFAs) of 19.3\%, while MUFAs 18:1 accounted for 20.7 and $16: 1$ for $0.7 \%$. Pasteurised milk of the dairy plant $B$ also showed the lowest level of n-3 as compared to milk of other establishments. In particular ALA was $0.2 \%$, while the content of LA was $2.7 \%$. In this milk the highest value (6.8) for the nutritional index n- 6/n-3 and the lowest for the AI (2.3) were observed.

The results obtained in samples originated from plants with higher production volume (CG) where more homogeneous. The milk pasteurised at high temperature (C) is characterised by a limited amount of PUFAs (4.7\%), in particular of LA (2.2\%). There is also the lowest value for the $n-6 / n-3$ nutritional index (2.8). High temperature pasteurised milk (plant D) showed the highest content of palmitic acid (25.9\%). UHT milk (plant E) had the lowest values of SCFAs (16.8\%), LCFAs (9.9\%), rumenic acid (0.4\%) and vaccenic acid (0.7\%). Higher values of $10 t-18: 1$ and AI (2.9) were also observed.

In semi-skimmed milk samples (dairy F and G), the fat content was 1.6 and $1.5 \mathrm{mg} / 100 \mathrm{~mL}$ of milk. Milk obtained from dairy $\mathrm{F}$ showed higher concentration of PUFAs (6.7\%) and EFAs metabolism products n-6 (3.1\%) and n-3 (1.1\%). There was also the highest quantity of $t$-FAs (4.2\%) and CLA (1.1\%), while the TI showed its lowest value (2.7). Partially skimmed milk samples (dairy G) showed lower concentrations of MUFAs (19.7\%) and particularly of oleic acid (16.6\%), while the values of

Table 1. Types of 49 fluid goat milk samples collected from different dairy plants.

\begin{tabular}{lllc} 
Dairy plant & Location & Type of milk & Samples (n) \\
A & Sardinia & Fresh pasteurised & 6 \\
B & Sardinia & Organic fresh pasteurised & 6 \\
\hline C & Sardinia & Whole pasteurised at high temperature & 6 \\
D & Campania & Whole pasteurised at high temperature & 6 \\
\hline E & Sardinia & Whole UHT & 11 \\
F & France & Semi-skimmed UHT & 10 \\
\hline G & France & Semi-skimmed UHT & 4 \\
\hline
\end{tabular}

UHT, ultrahigh temperature.

Unt, ultrahigh tenperature.

Table 2. Total fat and lipids profile (g/100 mL of milk) of 49 fluid goat milk samples.

\begin{tabular}{|c|c|c|c|c|c|c|c|}
\hline & & & & Dairy plant & & & \\
\hline & A & B & C & D & $\mathbf{E}$ & $\mathbf{F}$ & G \\
\hline Fat & $3.90 \pm 0.23$ & $5.04 \pm 0.69$ & $3.42 \pm 0.07$ & $3.05 \pm 0.02$ & $3.32 \pm 0.28$ & $1.60 \pm 0.16$ & $1.51 \pm 0.08$ \\
\hline SFAs & $2.77 \pm 0.18$ & $3.35 \pm 0.51$ & $2.39 \pm 0.04$ & $2.09 \pm 0.02$ & $2.28 \pm 0.18$ & $1.07 \pm 0.07$ & $1.05 \pm 0.05$ \\
\hline SCFAs & $0.73 \pm 0.05$ & $0.97 \pm 0.18$ & $0.64 \pm 0.03$ & $0.52 \pm 0.01$ & $0.56 \pm 0.04$ & $0.30 \pm 0.05$ & $0.29 \pm 0.03$ \\
\hline MCFAs & $1.54 \pm 0.12$ & $1.83 \pm 0.28$ & $1.33 \pm 0.03$ & $1.23 \pm 0.02$ & $1.39 \pm 0.14$ & $0.60 \pm 0.03$ & $0.60 \pm 0.02$ \\
\hline LCFAs & $0.50 \pm 0.03$ & $0.54 \pm 0.07$ & $0.42 \pm 0.02$ & $0.34 \pm 0.01$ & $0.33 \pm 0.03$ & $0.17 \pm 0.01$ & $0.16 \pm 0.01$ \\
\hline$c$-MUFAs & $0.77 \pm 0.04$ & $1.20 \pm 0.21$ & $0.70 \pm 0.05$ & $0.65 \pm 0.01$ & $0.72 \pm 0.08$ & $0.34 \pm 0.03$ & $0.30 \pm 0.01$ \\
\hline PUFAs & $0.19 \pm 0.01$ & $0.25 \pm 0.03$ & $0.16 \pm 0.01$ & $0.16 \pm 0.01$ & $0.16 \pm 0.01$ & $0.11 \pm 0.05$ & $0.09 \pm 0.01$ \\
\hline n-6 & $0.10 \pm 0.00$ & $0.15 \pm 0.02$ & $0.08 \pm 0.01$ & $0.08 \pm 0.00$ & $0.09 \pm 0.01$ & $0.05 \pm 0.01$ & $0.04 \pm 0.00$ \\
\hline n-3 & $0.04 \pm 0.00$ & $0.02 \pm 0.01$ & $0.03 \pm 0.00$ & $0.03 \pm 0.00$ & $0.02 \pm 0.01$ & $0.02 \pm 0.01$ & $0.01 \pm 0.00$ \\
\hline CLA & $0.02 \pm 0.00$ & $0.04 \pm 0.01$ & $0.02 \pm 0.00$ & $0.02 \pm 0.00$ & $0.02 \pm 0.00$ & $0.02 \pm 0.01$ & $0.02 \pm 0.00$ \\
\hline$t$-FAs & $0.12 \pm 0.01$ & $0.18 \pm 0.02$ & $0.11 \pm 0.01$ & $0.10 \pm 0.00$ & $0.12 \pm 0.02$ & $0.07 \pm 0.02$ & $0.05 \pm 0.00$ \\
\hline
\end{tabular}

SFAs, saturated fatty acids; SCFAs, short chain fatty acids (SFAs with C=4-10); MCFAs, medium chain fatty acids (SFAs with C=11-16); LCFAs, long chain fatty acids (SFAs with C=17-24); $c$-MUFAs, cis-mono-unsaturated fatty acids; PUFAs, poli-unsaturated fatty acids; n-6, 18:2+18:3c6,c9,c12+20:3HOMO-G+20:4+22:4+20:2; n-3, 18:3c9,c12,c15+20:5+22:5+22:6; CLA, conjugated linoleic acid; $t$-FAs, trans-fatty acids. 
rumenic (0.6\%) and vaccenic acid (1.1\%) were higher.

\section{Discussion}

Whole fresh pasteurised milk originated from small or very small establishments (A, B), where no standardisation of fat content is performed, showed a higher fat content $(>3.5 \%)$ as compared to larger dairies. Regulation EC No. 1234/2007 (European Commission, 2007) sets fat content limits for standardised milk $\geq 3.5 \%$ for whole milk and of $1.5-1.8 \%$ for semiskimmed milk. Whole milk samples (C-E) were lower than the limits, while semi-skimmed milk samples (F and G) were always within the defined range.

The relation between dietary SFAs and CVD is a topic of great public interest. The SFAs mean content was $68.4 \%$ of total milk FAs, which is lower than previously reported in raw goat milk, $76.8 \%$ by Luna et al.(2008) and
$70.4 \%$ by Ceballos et al. (2009). The SFAs content of fluid goat milk samples was comparable to heat treated fluid cow milk ranging between 62.4 and 74.1\% (O'Donnell et al., 2010; 0'Donnell-Megaro et al.; 2011; Butler et al., 2011). The SCFAs content of fluid goat milk was $18.1 \%$, which is higher than fluid cow's milk (5.26-10.06\%) (0’Donnell et al., 2010; 0'Donnell-Megaro et al., 2011; Butler et al., 2011). The MCFAs mean content was $39.3 \%$, lower than observed in raw goat milk (40.744.4\%) and fluid bovine milk (40.9-53.0\%) (Park et al., 2007; Luna et al., 2008; Ceballos et al., 2009; 0'Donnell et al., 2010; 0'DonnellMegaro et al., 2011; Butler et al., 2011). The presence of higher content in SCFAs and lower in MCFAs observed in the present study supports the benefic effect of goat milk in the reduction of plasma cholesterol levels (Krauss et al., 2000). The mean content of $t$-FAs, mainly represented by 11 trans-18:1, was $3.6 \%$ of total milk FAs within the range for ruminants, from 2.5 to $5.0 \%$ of total FAs (Park et al., 2007). $T$-FAs are considered to be harmful to human health because associated with the risk of coronary heart disease and myocardial infarction (Ascherio et al., 1994). However, CHD risk is associated with consumption of $t$-FAs tipically from industrial sources characterised by a high content of 9trans and 10trans-18:1 (Destaillats et al., 2008). The possible indication on the label of trans fatty acids content, as already adopted by Canada and United States, is considered by Regulation EU No. 1169/2011 (European Commission, 2011). The importance of the 11trans-18:1 is also linked to its role as a precursor of 9cis,11trans-18:2 CLA, studied for its many positive effects (Bhattacharya et al., 2006). Total CLA in the samples analysed in this study showed a mean content of $0.8 \%$. Park et al. (2007) reported a mean content of $0.65 \%$ of total CLA in goat raw milk. Available information refers to bovine commercial milk, with a total CLA content of 1.89\% (Precht and Molkentin, 2000).

The average values of the nutritional indices were 2.71 and 2.95 for $\mathrm{AI}$ and $\mathrm{TI}$, respectively, in agreement with previous stud-

Table 3. Fatty acid composition (g/100 $\mathrm{g}$ total fatty acids) and nutritional indices of 49 fluid goat milk samples.

\begin{tabular}{|c|c|c|c|c|c|c|c|}
\hline FA & A & B & C & $\begin{array}{l}\text { Dairy plant } \\
\text { D }\end{array}$ & E & $\mathrm{F}$ & G \\
\hline 4:0 & $2.91 \pm 0.12$ & $2.79 \pm 0.08$ & $2.92 \pm 0.07$ & $2.78 \pm 0.08$ & $2.68 \pm 0.16$ & $2.94 \pm 0.54$ & $2.78 \pm 0.19$ \\
\hline $6: 0$ & $2.97 \pm 0.13$ & $3.04 \pm 0.15$ & $2.93 \pm 0.12$ & $2.67 \pm 0.06$ & $2.64 \pm 0.14$ & $2.90 \pm 0.38$ & $2.93 \pm 0.13$ \\
\hline $8: 0$ & $3.00 \pm 0.12$ & $3.24 \pm 0.28$ & $2.98 \pm 0.20$ & $2.68 \pm 0.05$ & $2.65 \pm 0.14$ & $2.89 \pm 0.17$ & $3.02 \pm 0.10$ \\
\hline 10:0 & $9.82 \pm 0.37$ & $10.05 \pm 1.24$ & $9.64 \pm 0.62$ & $8.89 \pm 0.16$ & $8.69 \pm 0.29$ & $9.15 \pm 0.27$ & $9.98 \pm 0.12$ \\
\hline 12:0 & $3.86 \pm 0.18$ & $3.93 \pm 0.61$ & $3.94 \pm 0.23$ & $4.03 \pm 0.03$ & $5.91 \pm 1.42$ & $4.10 \pm 0.28$ & $4.49 \pm 0.14$ \\
\hline 14:0 & $8.98 \pm 0.15$ & $8.48 \pm 0.60$ & $9.27 \pm 0.18$ & $9.56 \pm 0.07$ & $10.61 \pm 0.74$ & $9.15 \pm 0.73$ & $9.82 \pm 0.23$ \\
\hline 15:0 & $0.76 \pm 0.03$ & $0.56 \pm 0.05$ & $0.84 \pm 0.02$ & $0.85 \pm 0.01$ & $0.79 \pm 0.08$ & $0.75 \pm 0.06$ & $0.79 \pm 0.04$ \\
\hline 16:0 & $25.78 \pm 0.66$ & $23.33 \pm 0.56$ & $24.81 \pm 0.33$ & $25.89 \pm 0.43$ & $24.45 \pm 1.78$ & $23.67 \pm 2.21$ & $24.23 \pm 0.50$ \\
\hline 17:0 & $0.55 \pm 0.03$ & $0.47 \pm 0.05$ & $0.60 \pm 0.02$ & $0.55 \pm 0.01$ & $0.45 \pm 0.11$ & $0.50 \pm 0.02$ & $0.55 \pm 0.05$ \\
\hline 18:0 & $11.35 \pm 0.24$ & $9.57 \pm 0.51$ & $10.83 \pm 0.31$ & $9.60 \pm 0.27$ & $8.73 \pm 0.82$ & $8.91 \pm 0.98$ & $9.43 \pm 0.26$ \\
\hline 20:0 & $0.36 \pm 0.02$ & $0.28 \pm 0.05$ & $0.38 \pm 0.04$ & $0.34 \pm 0.04$ & $0.26 \pm 0.04$ & $0.26 \pm 0.12$ & $0.25 \pm 0.02$ \\
\hline 22:0 & $0.12 \pm 0.02$ & $0.10 \pm 0.02$ & $0.12 \pm 0.01$ & $0.11 \pm 0.01$ & $0.11 \pm 0.01$ & $0.17 \pm 0.11$ & $0.17 \pm 0.04$ \\
\hline $24: 0$ & $0.14 \pm 0.02$ & $0.19 \pm 0.02$ & $0.14 \pm 0.02$ & $0.12 \pm 0.02$ & $0.15 \pm 0.02$ & $0.20 \pm 0.11$ & $0.14 \pm 0.04$ \\
\hline $9 \mathrm{c}-14: 1, \mathrm{MA}$ & $0.09 \pm 0.00$ & $0.12 \pm 0.01$ & $0.09 \pm 0.00$ & $0.12 \pm 0.01$ & $0.17 \pm 0.04$ & $0.13 \pm 0.02$ & $0.13 \pm 0.02$ \\
\hline $9 \mathrm{c}-16: 1, \mathrm{PA}$ & $0.44 \pm 0.03$ & $0.68 \pm 0.06$ & $0.45 \pm 0.03$ & $0.54 \pm 0.03$ & $0.66 \pm 0.11$ & $0.51 \pm 0.07$ & $0.47 \pm 0.06$ \\
\hline $9 \mathrm{c}-18: 1, \mathrm{OA}$ & $17.51 \pm 0.52$ & $20.67 \pm 2.86$ & $18.05 \pm 1.33$ & $18.40 \pm 0.46$ & $18.61 \pm 0.60$ & $17.08 \pm 1.65$ & $16.65 \pm 0.38$ \\
\hline 18:2, LA & $2.35 \pm 0.19$ & $2.66 \pm 0.07$ & $2.16 \pm 0.16$ & $2.23 \pm 0.06$ & $2.17 \pm 0.13$ & $2.38 \pm 0.25$ & $2.36 \pm 0.06$ \\
\hline 18:3, ALA & $0.73 \pm 0.05$ & $0.24 \pm 0.03$ & $0.67 \pm 0.04$ & $0.66 \pm 0.02$ & $0.44 \pm 0.16$ & $0.54 \pm 0.10$ & $0.55 \pm 0.02$ \\
\hline $20: 4, \mathrm{AA}$ & $0.14 \pm 0.02$ & $0.19 \pm 0.02$ & $0.14 \pm 0.02$ & $0.12 \pm 0.02$ & $0.15 \pm 0.02$ & $0.20 \pm 0.11$ & $0.14 \pm 0.04$ \\
\hline 20:5, EPA & $0.06 \pm 0.02$ & $0.08 \pm 0.05$ & $0.08 \pm 0.05$ & $0.09 \pm 0.03$ & $0.08 \pm 0.03$ & $0.16 \pm 0.12$ & $0.10 \pm 0.03$ \\
\hline 22:6, DHA & $0.06 \pm 0.03$ & $0.06 \pm 0.02$ & $0.06 \pm 0.02$ & $0.09 \pm 0.05$ & $0.08 \pm 0.03$ & $0.16 \pm 0.09$ & $0.10 \pm 0.03$ \\
\hline $9 c, 11 t-18: 2$, RA & $0.41 \pm 0.03$ & $0.55 \pm 0.05$ & $0.41 \pm 0.03$ & $0.55 \pm 0.02$ & $0.40 \pm 0.06$ & $0.56 \pm 0.05$ & $0.62 \pm 0.05$ \\
\hline $10 \mathrm{t}-18: 1$ & $0.20 \pm 0.02$ & $0.40 \pm 0.02$ & $0.21 \pm 0.01$ & $0.23 \pm 0.01$ & $0.55 \pm 0.26$ & $0.39 \pm 0.06$ & $0.27 \pm 0.03$ \\
\hline 11t-18:1, VA & $0.88 \pm 0.06$ & $1.02 \pm 0.06$ & $0.84 \pm 0.10$ & $0.97 \pm 0.04$ & $0.69 \pm 0.12$ & $1.03 \pm 0.12$ & $1.09 \pm 0.07$ \\
\hline$n-6 / n-3$ & $2.81 \pm 0.25$ & $6.82 \pm 1.42$ & $2.79 \pm 0.31$ & $2.77 \pm 0.16$ & $3.79 \pm 0.80$ & $3.19 \pm 0.89$ & $3.39 \pm 0.26$ \\
\hline $\mathrm{AI}$ & $2.80 \pm 0.13$ & $2.27 \pm 0.38$ & $2.76 \pm 0.20$ & $2.74 \pm 0.05$ & $2.91 \pm 0.16$ & $2.55 \pm 0.24$ & $2.90 \pm 0.06$ \\
\hline $\mathrm{TI}$ & $3.20 \pm 0.13$ & $2.78 \pm 0.27$ & $3.09 \pm 0.14$ & $2.97 \pm 0.09$ & $3.01 \pm 0.12$ & $2.70 \pm 0.39$ & $3.07 \pm 0.11$ \\
\hline
\end{tabular}

FA, fatty acid; MA, myristoleic acid; PA, palmitoleic acid; OA, oleic acid; LA, linoleic acid; ALA, $\alpha$-linolenic acid; AA, arachidonic acid; EPA, eicosapentaenoic acid; DHA, docosahexaenoic acid; RA, rumenic acid; VA, vaccenic acid; AI, atherogenic index; TI, thrombogenic index. 
ies performed on goats milk (Bouattour et al., 2008; Osmari et al., 2011). Low values of these indices are usually observed in foods that provide a low intake of undesirable fats and are therefore associated with a reduced risk of cardiovascular disease (Ulbricht and Southgate, 1991).

\section{Conclusions}

Based on the quantity of fatty acids, small scale productions, where no standardisation of milk fat content was applied, showed the greatest variability, while industrial plants resulted more homogeneous and undifferentiated. Considering the increasing importance of goat milk on the international market, further research is needed in order to characterise the lipids profile of heat treated milk. Special attention should be paid on the fatty acids which have an impact on human nutrition and health. In order to have a commercial milk with a natural high content of such benefic fatty acids, it is essential to standardise the production system. Fluid milk market also require to put in place a reorganisation of goat milk supply chain to be able to support the demand of large scale distribution.

\section{References}

Ascherio A, Hennekens CH, Buring JE, Master C, Stampfer MJ, Willett WC, 1994. Trans-fatty acids intake and risk of myocardial infarction. Circulation 89:94-101.

Astrup A, Dyerberg J, Elwood P, Hermansen K, Hu FB, Jakobsen MU, Kok FJ, Krauss RM, Lecerf JM, LeGrand P, Nestel P, Risérus U, Sanders T, Sinclair A, Stender S, Tholstrup T, Willett WC, 2011. The role of reducing intakes of saturated fat in the prevention of cardiovascular disease: where does the evidence stand in 2010? Am J Clin Nutr 93:684-8.

Barnes SF, 1951. Milk pasteurization in Malta Aust. J Dairy Technol 6:3-5.

Bhattacharya A, Banu J, Rahman M, Causey J, Fernandes G, 2006. Biological effects of conjugated linoleic acids in health and disease. $\mathrm{J}$ Nutr Biochem 17:789-810.

Bligh EG, Dyer WJ, 1959. A rapid method of total lipid extraction and purification. Can J Biochem Phys 37:911-7.

Bouattour MA, Casals R, Albanell E, Such X, Caja G, 2008. Feeding soybean oil to dairy goats increases conjugated linoleic acid in milk. $\mathrm{J}$ Dairy Sci 91:2399-407.

Butler G, Stergiadis S, Seal C, Eyre M, Leifert C, 2011. Fat composition of organic and conventional retail milk in northeast England. $\mathrm{J}$ Dairy Sci 94:24-36.
Ceballos LS, Morales ER, de la Torre Adarve G, Díaz Castro J, Pérez Martínez L, Remedios Sanz Sampelayo M, 2009. Composition of goat and cow milk produced under similar conditions and analysed by identical methodology. J Food Compos Anal 22:322-9.

Cruz-Hernandez C, Deng Z, Zhou J, Hill AR, Yurawecz MP, Delmonte P, Mossoba MM, Dugan MER, Kramer JKG, 2004. Methods to analyze conjugated linoleic acids (CLA) and trans-18:1 isomers in dairy fats using a combination of GC, silver ion TLC-GC, and silver ion HPLC. J AOAC Int 87:545-62.

DeFilippis AP, Sperling LS, 2006. Understanding omega-3's. Am Heart J 151:564-70.

Delmonte P, Fardin Kia AR, Kramer JKG, Mossoba MM, Sidisky L, Rader JI, 2011. Separation characteristics of fatty acid methyl esters using SLB-IL111, a new ionic liquid coated capillary gas chromatographic column. J Chromatogr A 1218:545-54.

Destaillats F, JM Chardigny, C Malpuech-Brugère, Sébédio J-L, Bezelgues J-B, Dionisi F, Bauman DE, 2008. Unraveling the complexity of health effects of trans fatty acids: Insight from the TRANSFACT study. Lipid Tech 20:129-31.

Ervin RB, Wright JD, Wang CY, KennedyStephenson J, 2004. Dietary intake of fats and fatty acids for the United States population: 1999-2000. Adv Datab R 348:1-6.

European Commission, 2007. Commission Regulation of 22 October 2007 establishing a common organisation of agricultural markets and on specific provisions for certain agricultural products (Single CMO Regulation), 1234/2007/EC. In: Official Journal, L 299/1, 16/11/2007.

European Commission, 2011. European Parliament and Council Regulation of 25 October 2011on the provision of food information to consumers, amending Regulations (EC) No 1924/2006 and (EC) No 1925/2006 of the European Parliament and of the Council, and repealing Commission Directive 87/250/EEC, Council Directive 90/496/EEC, Commission Directive 1999/10/EC, Directive 2000/13/EC of the European Parliament and of the Council, Commission Directives 2002/67/EC and 2008/5/EC and Commission Regulation (EC) No 608/2004, 1169/2011/EU. In: Official Journal, L 304/18, 22/11/2011.

Haug A, Hostmark AT, Harstad OM, 2007. Bovine milk in human nutrition. A review. Lipids Health Dis 6:25-41.

Huth PJ, DiRienzo DB, Miller GD, 2006. Major scientific advances with dairy foods in nutrition and health. J Dairy Sci 89:1207-21.

Krauss RM, Eckel RH, Howard B, Appel LJ, Daniels SR, Deckelbaum RJ, Erdman JW Jr, Kris-Etherton P, Goldberg IJ, Kotchen TA, Lichtenstein AH, Mitch WE, Mullis R, Robinson K, Wylie-Rosett J, St Jeor S, Suttie J, Tribble DL, Bazzarre TL, 2000. AHA dietary guidelines revision 2000: a statement for healthcare professionals from the Nutrition Committee of the American Heart Association. Circulation 102:2284-99.

Kris-Etherton PM, Harris WS, Appel LJ, 2003. Omega-3 fatty acids and cardiovascular disease: New recommendations from the American Heart Association. Arterioscler Thromb 23:151-2.

Luna P, Bach A, Juàrez M, de la Fuente MA, 2008. Effect of a diet enriched in whole linseed and sunflower oil on goat milk fatty acid composition and conjugated linoleic acid isomer profile. J Dairy Sci 91:20-8.

Menendez JA, Papadimitropoulou A, Vellón L, Lupu R, 2006. A genomic explanation connecting "Mediterranean diet," olive oil and cancer: oleic acid, the main monounsaturated fatty acid of olive oil, induces formation of inhibitory "PEA3 transcription factor-PEA3 DNA binding site" complexes at the Her2/neu (erbB-2) oncogene promoter in breast, ovarian and stomach cancer cells. Eur $\mathrm{J}$ Cancer 42:2425-32.

Merlo B , 2001. Full-fat UHT goat milk that is also Italian. Latte 26:30-5.

O'Donnell AM, Spatny KP, Vicini JL, Bauman DE, 2010. Survey of the fatty acid composition of retail milk differing in label claims based on production management practices. J Dairy Sci 93:1918-25.

0'Donnell-Megaro AM, Barbano DM, Bauman DE, 2011. Survey of the fatty acid composition of retail milk in the United States including regional and seasonal variations. J Dairy Sci 94:59-65.

Osmari EK, Cecato U, Macedo FAF, Souza NE, 2011. Nutritional quality indices of milk fat from goats on diets supplemented with different roughages. Small Ruminant Res 98:128-32.

Park YW, Juàrez M, Ramos M, Haenlein GFW, 2007. Physico-chemical characteristics of goat and sheep milk. Small Ruminant Res 68:88-113.

Parodi PW, 2003. Conjugated linoleic acid in food. In: Christie WW, Sebedio JL and Adolf R0, eds. Advances in conjugated linoleic acid research. AOCS Press, Champaign, IL, pp 101-22.

Precht D, Molkentin J, 2000. Frequency distribution of conjugated linoleic acid and trans fatty acid contents in European bovine milk fats. Milchwissenschaft 55:687-91.

Simopoulos A, 2002. The importance of the ratio of omega-6/omega-3 essential fatty acids. Biomed. Pharmacotherapy 56:365-79.

Ulbricht TLV, Southgate DAT, 1991. Coronary heart disease: seven dietary factors. Lancet 338:985-92. 